\title{
Analytical Performance of Four Polymerase Chain Reaction (PCR) and Real Time PCR (qPCR) Assays for the Detection of Six Leishmania Species DNA in Colombia
}

\author{
Cielo M. León ${ }^{1,2}$, Marina Muñoz ${ }^{1}$, Carolina Hernández ${ }^{1,3}$, Martha S. Ayala4, \\ Carolina Flórez ${ }^{4}$, Aníbal Teherán ${ }^{5,6}$, Juan R. Cubides ${ }^{3,7}$ and Juan D. Ramírez ${ }^{\text {* }}$
}

1 Universidad del Rosario, Facultad de Ciencias Naturales y Matemáticas, Programa de Biología, Grupo de Investigaciones Microbiológicas-UR (GIMUR), Bogotá, Colombia, ${ }^{2}$ Facultad de Medicina, Universidad Nacional de Colombia, Bogotá, Colombia, ${ }^{3}$ Programa de Doctorado en Ciencias Biomédicas y Biológicas, Universidad del Rosario, Bogotá, Colombia, ${ }^{4}$ Grupo de Parasitología, Instituto Nacional de Salud, Bogotá, Colombia, ${ }^{5}$ Residente de Medicina de Emergencias, Escuela de Medicina y Ciencias de la Salud, Universidad del Rosario, Bogotá, Colombia, ${ }^{6}$ Grupo de Investigación COMPLEXUS, Fundación Universitaria Juan N. Corpas, Bogotá, Colombia, ${ }^{7}$ Molecular Biology and Immunology Department, Fundación Instituto de Inmunología de Colombia (FIDIC), Bogotá, Colombia

OPEN ACCESS

Edited by:

Celio Geraldo Freire De Lima, Federal University of Rio de Janeiro,

Brazil

Reviewed by:

Luca Galluzzi,

University of Urbino, Italy

Laurence S. Dawkins-Hall,

University of Leicester,

United Kingdom

*Correspondence:

Juan D. Ramírez

juand.ramirez@urosario.edu.co

Specialty section: This article was submitted to Infectious Diseases,

a section of the journal

Frontiers in Microbiology

Received: 09 August 2017 Accepted: 19 September 2017

Published: 04 October 2017

Citation:

León CM, Muñoz M, Hernández $C$, Ayala MS, Flórez C, Teherán A, Cubides JR and Ramírez JD (2017)

Analytical Performance of Four

Polymerase Chain Reaction (PCR) and Real Time PCR (qPCR) Assays for the Detection of Six Leishmania

Species DNA in Colombia.

Front. Microbiol. 8:1907.

doi: 10.3389/fmicb.2017.01907
Leishmaniasis comprises a spectrum of parasitic diseases caused by protozoans of the genus Leishmania. Molecular tools have been widely employed for the detection of Leishmania due to its high sensitivity and specificity. However, the analytical performance of molecular platforms as PCR and real time PCR ( $\mathrm{PPCR}$ ) including a wide variety of molecular markers has never been evaluated. Herein, the aim was to evaluate the analytical performance of 4 PCR-based assays (designed on four different targets) and applied on conventional and real-time PCR platforms. We evaluated the analytical performance of conventional PCR and real time PCR, determining exclusivity and inclusivity, Anticipated Reportable Range (ARR), limit of detection (LoD) and accuracy using primers directed to KDNA, HSP70, 18S and ITS-1 targets. We observed that the KDNA was the most sensitive but does not meet the criterion of exclusivity. The HSP70 presented a higher LoD in conventional PCR and APCR in comparison with the other markers $\left(1 \times 10^{1}\right.$ and $1 \times 10^{-1}$ equivalent parasites $/ \mathrm{mL}$ respectively) and had a higher coefficient of variation in qPCR. No statistically significant differences were found between the days of the test with the four molecular markers. The present study revealed that the $18 \mathrm{~S}$ marker presented the best performance in terms of analytical sensitivity and specificity for the GPCR in the species tested (species circulating in Colombia). Therefore, we recommend to explore the analytical and diagnostic performance in future studies using a broader number of species across America.

Keywords: Leishmania, molecular diagnosis, analytical performance, PCR, qPCR

\section{INTRODUCTION}

Leishmaniasis comprises a spectrum of diseases caused by a single-celled flagellate protozoan of the genus Leishmania and transmitted by the bite of a female phlebotomine of the family Psychodidae (Akhoundi et al., 2016). About 20 species of Leishmania are responsible for a wide range of clinical manifestations in humans and vertebrates. Three clinical manifestations exist: (i) cutaneous 
leishmaniasis (CL) that causes skin lesions, (ii) mucocutaneous leishmaniasis (MCL) characterized by localized mucosal lesions and (iii) visceral leishmaniasis (VL), which is responsible for a severe chronic infection of the reticuloendothelial system that leads to death if it is not treated timely (Bezerra-Vasconcelos et al., 2011). CL is the most common form, characterized by the presence of ulcerative lesions leading to disfiguring and/or incapacitating scars (Desjeux, 2001; Alvar et al., 2012). This neglected tropical disease is considered endemic in large tropical, subtropical and Mediterranean basins (Jara et al., 2013; Akhoundi et al., 2017).

According to data reported by the World Health Organization (WHO), it is prevalent over 98 countries. It is estimated that $\sim$ 350 million people are at risk of infection and $\sim 12$ million cases with an annual (estimated) incidence of 0.7-1.2 million cases of CL and 0.2-0.4 million of VL (Alvar et al., 2012; Pan American Health Organization, [WHO], 2013) are reported. For the old world, CL is most commonly associated with Leishmania major, L. tropica, and L. aethiopica species. For the Americas, localized CL is caused by multiple species of the subgenus Leishmania and Viannia (L. mexicana, L. braziliensis, L. panamensis, L. amazonensis, L. colombiensis, L. guyanensis, L. peruviana among others). MCL is most frequently associated with L. braziliensis and L. panamensis species (Pan American Health Organization, [WHO], 2013). The control of leishmaniasis is complicated by the variety of Leishmania species and the different clinical forms as well as by unique epidemiological patterns of the disease. In many regions of the New World, two or more species are often sympatric (Hashiguchi et al., 2017), for example, Colombia is the country with the largest number of Leishmania species that affect humans in the world and complicates the control of this pathology (nine species in total) (Ramirez et al., 2016).

Traditionally, microscopic examination is considered the diagnostic routine method for CL and MCL. However, despite its high specificity (100\%), its sensitivity is low. Several authors report that the sensitivity of direct microscopic examination varies between 74.4 and $40 \%$, and these values depend on aspects related to the evolution of the skin lessions, the localization where the sample is taken and the expertise of the microscopist (Bensoussan et al., 2006; Szargiki et al., 2009; Goto and Lauletta Lindoso, 2012). Therefore, more sensitive methods such as the polymerase chain reaction (PCR) have been developed as an alternative for the diagnosis and identification of Leishmania species. PCR platforms show sensitivity values between 92 and 100\% and specificity of 100\% (Reithinger and Dujardin, 2007; Shahbazi et al., 2008; Mohammadiha et al., 2013; Adams et al., 2014; Munoz et al., 2016). For the amplification of DNA fragments of Leishmania species, the use of genetic targets such as kinetoplast DNA (kDNA), which has a sensitivity of $97 \%$ and a specificity of $87 \%$, has been reported in several studies (Marques et al., 2001; Rodriguez et al., 2002; Jara et al., 2013). The Heat Shock Protein $70 \mathrm{kDa}$ (HSP70) also reflects a sensitivity of $95 \%$ and a specificity of $100 \%$ (Garcia et al., 2007; Montalvo et al., 2014).

The internal transcribed spacer 1 (ITS-1) with 40 and 96\% respectively (Marfurt et al., 2003; Kumar et al., 2007;
Ovalle Bracho et al., 2007) and finally the small 18S ribosomal subunit with a similar behavior as $\mathrm{kDNA}$ in terms of sensitivity and specificity (Adams et al., 2014). These are the most commonly used markers for the identification of Leishmania DNA by PCR and Real Time PCR. However, these studies only report aspects related to the sensitivity and specificity of the technique. Also, the published studies only evaluate maximum two markers per technique/platform and an adequate evaluation of the analytical performance of the technique and genetic targets employed has never been conducted. This is of critical relevance, because those aspects are mandatory to determine the analytical specificity and sensitivity of molecular methods (Berzunza-Cruz et al., 2002; Marfurt et al., 2003; Chargui et al., 2005; Bensoussan et al., 2006; Ovalle Bracho et al., 2007; Adams et al., 2014; Mouttaki et al., 2014).

The evaluation of the analytical performance is understood as the stage where reproducibility, inclusivity, exclusivity, accuracy and the limit of detection (LoD) are determined as the initial phase for the complete validation of a diagnostic method (NCCLS, 2004; Burd, 2010). Aspects already evaluated in other parasitic diseases such as Chagas disease and Toxoplasmosis (Sterkers et al., 2010; Ramirez et al., 2015). Due to the broad spectrum of leishmaniasis it is mandatory to find a highly sensitive method for diagnosis especially in endemic regions and in the New World where several species co-exist and cause CL (Pourmohammadi et al., 2010). To date, however, the lack of information on the evaluation of the analytical performance of the molecular diagnosis of CL has led to a biased use of PCR and qPCR with several molecular targets. Therefore, the purpose of the study was to evaluate the analytical performance of 4 PCR-based assays (designed on 4 different targets) and applied on conventional and real-time PCR platforms to detect the main New World Leishmania species causing CL in Colombia.

\section{MATERIALS AND METHODS}

\section{Ethics Statement}

This project has a certificate of approval from the ethics committee of the National University of Colombia number 002010-15 issued on February 12, 2015. This research study did not include samples from humans, animals or any individual.

\section{Reference Leishmania Strains}

Promastigote cultures of the major Leishmania reference strains frequently associated with CL and MCL in Colombia were donated by the International Center for Medical Research and Training (CIDEIM) that has already-existing collection of Leishmania [MHOM/BR/75/M2903 L. braziliensis, MHOM/PA/71/LS94 L. panamensis, MHOM/BR/75/M4147 L. guyanensis, MHOM/TN/80/IPT1 L. infantum, IFLA/BR/ 67/PH8 L. amazonensis and MHOM/BZ/82/BEL21 L. mexicana]. These strains were cloned and maintained in Novy, Nicolle and McNeal medium and Schneider medium supplemented with $20 \%$ fetal bovine serum (Microgen). There was no calculation of 
sample size due to the lack of availability of the 20 Leishmania species that infect humans. We decided to include six from the nine species of Leishmania that have been reported in Colombia.

\section{DNA Extraction and Serial Dilutions}

DNA extraction was performed according to the instructions of the High Pure PCR Template Preparation kit (Roche ${ }^{\circledR}$ Ref. 11796828001) from a stock that contained $10^{5}$ parasite equivalents/mL. DNA obtained from each reference strain was subsequently used to perform serial dilutions from $1 \times 10^{4}$ to $1 \times 10^{-2}$ parasites equivalents/mL to determine the analytical performance of molecular tests (PCR and qPCR).

\section{Selection of Molecular Targets}

To determine the analytical performance of the PCR and qPCR, four of the molecular markers commonly employed in the literature for molecular diagnosis were selected: (i) The gene coding for the heat shock protein of $70 \mathrm{kDa}$ (HSP70) (Garcia et al., 2007; Cruz et al., 2013); (ii) The ITS-1 (el Tai et al., 2000; Bensoussan et al., 2006; Eroglu et al., 2014; Hernández et al., 2014); (iii) The kinetoplast conserved region (kDNA) (Motazedian et al., 2002; Mary et al., 2004; Boggild et al., 2010; Jara et al., 2013) and (iv) The $18 \mathrm{~S}$ ribosomal RNA (18S) (Deborggraeve et al., 2008; BezerraVasconcelos et al., 2011; Cruz et al., 2013; Adams et al., 2014). These assays were conducted using primers previously reported (Supplementary Table S1) (Cruz et al., 2002; Medeiros et al., 2008).

\section{Molecular Tests (PCR and qPCR) Polymerase Chain Reaction}

The master mix (one per molecular target) was performed at a final volume of $15 \mu \mathrm{L}$ which contained $1.5 \mu \mathrm{L}$ of reaction buffer 10X (Invitrogen), $0.125 \mu \mathrm{L}$ of dNTPs $(10 \mathrm{mM}), 0.365 \mu \mathrm{L}$ of $\mathrm{MgCl} 2$ (25 mM), $0.5 \mu \mathrm{L}$ of each primer (HSP70f and HSP70r; KDNAf and kDNAr, LITS and L5.8S and R223 and R333) $(10 \mu \mathrm{M}), 0.05 \mu \mathrm{L}$ of Taq platinum DNA polymerase (Invitrogen) (0.1U) and $5 \mu \mathrm{L}$ of DNA. PCR was performed on T100 TM Thermal Cycler (Bio-Rad) using thermal cycle conditions as follows: An initial denaturation of $95^{\circ} \mathrm{C}$ for $5 \mathrm{~min}$ followed by 40 cycles at $95^{\circ} \mathrm{C}$ for $1 \mathrm{~min}, 1 \mathrm{~min}$ at $60^{\circ} \mathrm{C}$ and $1 \mathrm{~min}$ at $72^{\circ} \mathrm{C}$, with a final extension at $72^{\circ} \mathrm{C}$ per $10 \mathrm{~min}$ (For the LITS and L5.8S primers, the annealing temperature was $\left.56^{\circ} \mathrm{C}\right)$. To determine the band size, the amplification products were run on $2 \%$ agarose gels and stained with Sybr Safe.

\section{Real Time Polymerase Chain Reaction (qPCR)}

The master mix (one per molecular target) was performed at a final volume of $12 \mu \mathrm{L}$ which contained $5.0 \mu \mathrm{L}$ of Fast SYBR Green (Applied Biosystems Ref. 4385370), 0.6 $\mu \mathrm{L}$ of each of the same sets of primers used in PCR (shown above) and $2 \mu \mathrm{L}$ of DNA. The thermal profile consisted of the first stage of $50^{\circ} \mathrm{C}$ for $2 \mathrm{~min}$ followed by 40 cycles at $95^{\circ} \mathrm{C}$ for $30 \mathrm{~s}$ and $15 \mathrm{~s}$ at $60^{\circ} \mathrm{C}$. The qPCR was executed with a 7500 Fast Real-Time PCR System (Applied Biosystems). After the qPCR assay, a melting curve analysis was performed to detect any primer dimerization that could affect the efficiency of the assays.

\section{Analytical Specificity}

Analytical specificity was evaluated in terms of selectivity, given the test's responsiveness to selectively identify blank (Leishmania DNA) and non-blank (non-Leishmania DNA) sample sources. This feature includes:

\section{Inclusivity}

Describes the ability of the tests to detect the existing diversity of blank DNA (Leishmania DNA). Therefore, we performed standard PCR and qPCR with the four molecular markers (HSP70, ITS-1, 18S and kDNA) with the conditions described above to all the DNAs of the six Leishmania reference strains within a single day.

\section{Exclusivity}

Determines the non-response of DNA tests from closely related but not considered target sample sources. In this case, we selected microorganisms phylogenetically related to Leishmania and also those associated with differential diagnosis of CL. DNAs of parasites belonging to the order Kinetoplastida and obtained from a biological supply vendor (ATCC: The Global Bioresource Center) (ATCC PRA-330 Trypanosoma cruzi and ATCC 30032 Trypanosoma rangeli) and 8 microorganisms of differential diagnosis of CL (ATCC 25923 Staphylococcus aureus, ATCC 12344 Streptococcus pyogenes, ATCC 26033 Histoplasma capsulatum, ATCC 27294 Mycobacterium tuberculosis, ATCC 26329 Sporothrix schenckii and ATCC 18827 Fonsecaea pedrosoi) were subjected to conventional PCR and qPCR within a single day.

\section{Analytical Sensitivity}

The analysis of the analytical selectivity of the tests was directed to evaluate the measurement of error that can exist within specified limits. This feature includes:

\section{Anticipated Reportable Range (ARR)}

It refers to a range of concentrations in which the analyte can be determined with an adequate level of confidence and accuracy. To achieve this, seven serial dilutions $\left(1 \times 10^{4}\right.$ to $1 \times 10^{-2}$ parasites equivalents $/ \mathrm{mL}$ ) of each DNA of the Leishmania species (six species) were taken and subjected to the two molecular platforms (PCR and qPCR) with each of the four genetic targets (HSP70, kDNA, 18S and ITS-1). Each dilution was amplified in triplicate within a single day. For the case of conventional PCR, the minimum dilution to which a positive result (present of amplification band in electrophoresis) was consistently generated was identified. For qPCR, the reaction efficiency was evaluated through linear regression analysis, by calculating: (i) the slope of the linear logarithmic phase of the reaction, representing the accuracy and reproducibility of the results (values between -3.0 and $-3,6$, with -3.32 considered the expected value, corresponding to $100 \%$ efficiency), (ii) Y-intercept, corresponding to the theoretical detection limit of the reaction and (iii) correlation coefficient 
$\left(R^{2}\right)$, as a measure of linearity of the obtained curves and reflection of the reproducibility. Amplification efficiencies for the qPCR were graphically represented using the program GraphPad Prism 7.

\section{Limit of Detection (LoD)}

The LoD was calculated as the lowest dilution providing 95\% positive results, as established by NCCLS standards (NCCLS, 2004). Five serial dilutions of each DNA of the six Leishmania species were used and subjected to both molecular platforms with each of the four genetic targets. The amplification of each dilution was performed with 8 replicates and during 5 consecutive days. The LoD was determined by Probit Regression (Probit Minitab 15 software, United States).

\section{Accuracy}

Intra-assay reproducibility was assessed in terms of accuracy for each test. A dilution above and below the LoD of each DNA of the 6 Leishmania species were evaluated in triplicate for 10 days (one run per day) under the same conditions. For qPCR: Mean, Standard Deviation (SD) and Coefficient of Variation (CV) were estimated. For PCR, the presence/absence of a band was considered as a result for the subsequent analyses.

\section{Comparative Statistical Analysis}

The reproducibility of the qPCR results was evaluated through an initial analysis of variance homogeneity (based on the F2 distribution), followed by the implementation of comparison tests of means (considering the same or different variances, as the case may be). This set of analysis was aimed at comparing the means of $\mathrm{Ct}$ and their corresponding SD at three levels: (i) days, (ii) molecular marker and iii) evaluated species. A value of $p<0.05$ was considered statistically significant for this set of hypothesis tests.

The variation of the results depending on the concentration of the blank DNA (from each Leishmania species) was compared among the tests through descriptive analyzes. For conventional PCR the amplification's minimum dilution was determined by identifying the dilution in those results were consistently positive (>90\%) considering the total of developed trials: ARR (n: 3): 3 replicates in a single day; $\operatorname{LoD}(\mathrm{n}: 40$ ): 8 replicates during 5 days; Accuracy (n: 30): 3 replicates during 10 days. The dispersion measures (standard deviation 'SD') were calculated considering the positive result per total trials carried out per dilutions. For the qPCR the percentage of $\mathrm{CV}$ for each dilution was considered with respect to the maximum CV. The comparison between tests was carried out through a graphical representation, assigning one color per range of variation (every 20\%).

A one-way ANOVA test was used to explore relationships between species, target and parasite concentration with mean $\mathrm{Ct}$, and a Bonferroni-corrected factorial ANOVA (Post Hoc) to determine interactions between variables and to identify the most influential subcategories in the average Ct. Likewise, the interaction between these three variables was determined and a $p$-value $<0.01$ was established as significant.

\section{RESULTS}

\section{Inclusivity and Exclusivity for PCR and qPCR}

The tests of amplification from the DNAs of the 6 Leishmania species showed bands in the expected sizes for PCR and emission of fluorescence by qPCR across all the samples. When we retrieved the results from primer dimerization in the melting curve analysis, we only detected one peak excluding the previous premise. We concluded that both tests are inclusive. In terms of exclusivity, we observed that the test directed to kDNA was not exclusive in both platforms (PCR and qPCR) for the amplification of Leishmania, because we detected amplification with T. cruzi and M. tuberculosis DNAs (Supplementary Figure S1).

\section{ARR, LoD and Accuracy for PCR}

Consensus results were obtained from each dilution in each parameter evaluated (ARR, LoD and accuracy). The broadest ARR was observed with the kDNA marker obtaining amplification up to the $1 \times 10^{-1}$ dilution for all Leishmania species. For the ITS- 1 and $18 \mathrm{~S}$ markers the ARR is reported from the dilutions $1 \times 10^{4}$ to $1 \times 10^{0}$ and finally the marker HSP70 reports a low amplification range $\left(1 \times 10^{1}\right.$ parasite equivalents $/ \mathrm{mL}$ ) (Figure 1A). It was determined that the LoD for the markers kDNA, ITS-1 and 18S was up to the dilution $1 \times 10^{0}$ parasites equivalents $/ \mathrm{mL}$. For the HSP70 marker the LoD was $1 \times 10^{1}$ parasites equivalents $/ \mathrm{mL}$ for all Leishmania species (Figure 1B). These results are consistent with the ARR. As for the accuracy of the PCR during the 10 days of analysis, we concluded that it is low, neither homogeneous nor accurate data were observed as obtained in the ARR and LoD. In some days no amplification was obtained in the LoD (Figure 1C).

\section{ARR for qPCR}

The linear regression results for each molecular marker with its respective Leishmania species is shown in Figure 2. For the kDNA was observed that the amplification covers all dilutions of the ARR at a very early Ct (about 5-29). The values of slopes obtained for L. mexicana $(-2.73)$ and L. braziliensis $(-2.79)$ did not meet the expected values (Figure 2). In general, the technique presents good efficiency and reproducibility among replicates in L. amazonensis, L. guyanensis, L. panamensis and L. infantum. For the HSP70 marker, the slope values for L. braziliensis $(-2.93)$ were not within the range but the technique presents good efficiency and reproducibility between replicates in the other species. A good reproducibility of the technique with the ITS-1 marker was determined but a low efficiency in the L. amazonensis (-4.39) and L. guyanensis (-4.41) species. Finally, 18S showed a very homogeneous ARR among all species compared to $\mathrm{kDNA}$, HSP70 and ITS-1 (good reproducibility and efficiency of the technique) (Figure 2).

\section{LoD and Accuracy of qPCR}

To determine LoD of the qPCR platform, we first determined whether there was variation on the day of the tests. With the data presented in Supplementary Figure S2, a comparison test 


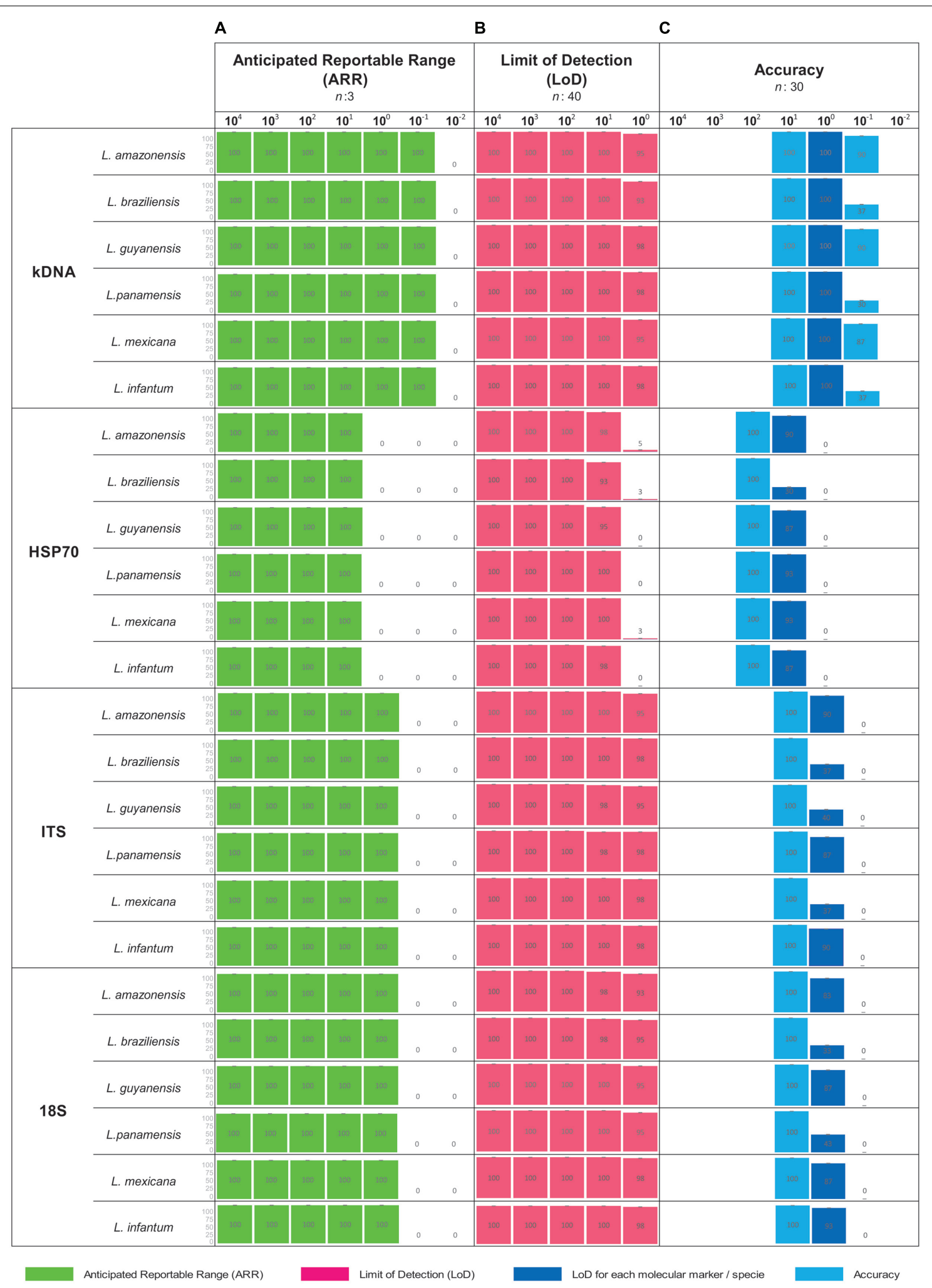

FIGURE 1 | Analytical sensitivity for conventional PCR. For each concentration a result is determined as positive when band presence was observed. (A) ARR determined from 7 serial dilutions analyzed for the four markers employed across the seven species studied; (B) LoD as a consensus of 5 serial dilutions for the four markers employed across the seven species studied and (C) Accuracy. Including dilution above and below the LoD for the four markers employed across the seven species studied. 


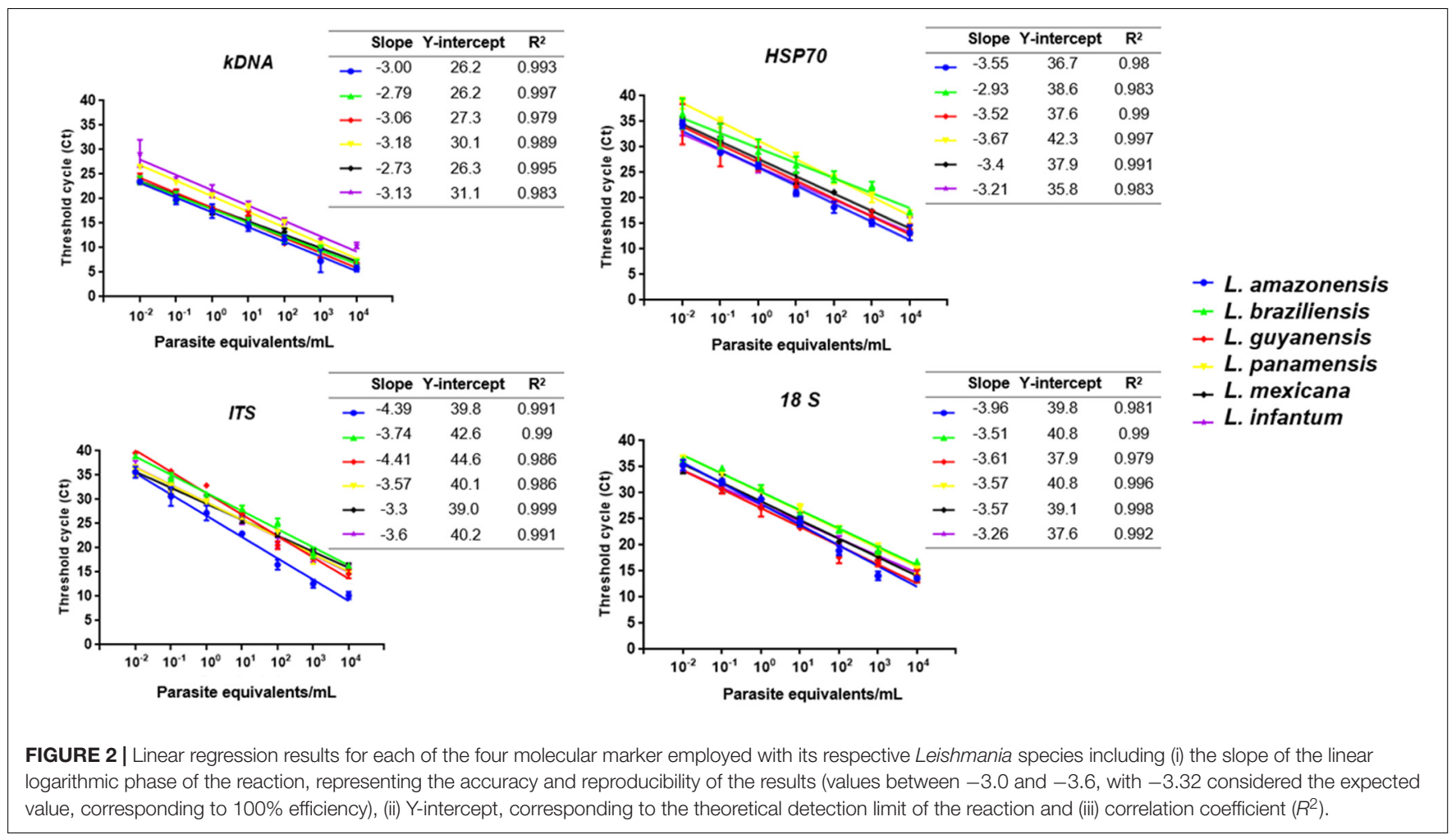

of variances with a $95 \%$ confidence interval was performed. We observed that no statistically significant differences were found between the days with the 4 molecular markers in the 5 serial dilutions ( $P$-value: 0.86$)$. A Probit regression analysis was then performed (Figure 3). The LoD for kDNA and $18 \mathrm{~S}$ in $\mathrm{qPCR}$ was $1 \times 10^{-2}$ parasites equivalents/mL and for HSP70 and ITS1 was $1 \times 10^{-1}$ parasites equivalents $/ \mathrm{mL}$. The complete results of Probit regression can be observed in Supplementary Table S2. Regarding the accuracy, Table 1 compare the means, SD and accuracy of the 6 species of Leishmania in each of the four molecular markers.

\section{Comparison of CV for PCR vs. QPCR}

Finally, a graphical representation of the percentage of variation of the two techniques was constructed (PCR vs. qPCR). Here, we identified that at very low dilutions the coefficient of variation between replicates increases (Figure 4). Percentages of variation of up to $100 \%$ were identified in markers such as ITS- 1 and $18 \mathrm{~S}$ in dilutions of $10^{-1}$ parasite equivalents $/ \mathrm{mL}$ in conventional PCR. However, in the case of $\mathrm{qPCR}, \mathrm{kDNA}$ and $18 \mathrm{~S}$ showed reduced percentages of variation, even when the test is performed to lower dilutions.

\section{Comparative Statistical Analyses}

A total of 2086 trials were performed to evaluate the accuracy, 4795 for the LoD and 500 for the ARR. Respectively, 74 (3.5\%), $5(0.1 \%)$, and $4(0.8 \%)$ trials where Ct was undetectable were presented. The $\mathrm{Ct}(\mathrm{SD})$ averages in the assessments of accuracy, LoD and ARR were 30.7 (0.11), 19.4 (6.5), 22.7 (8.31), respectively.
In the three evaluations, the univariate analyzes showed a relation between the average $\mathrm{Ct}$, the targets and concentrations ( $p$ : 0000). In the evaluation of the LoD, although with very low $R^{2}$ $(4.44 \%)$, it was identified relationship between the species and the average $\mathrm{Ct}$ (p: 0000). This relationship between the average $\mathrm{Ct}$ and the species was not identified in the other two assessments (data not shown). Interaction between the three factors was identified, except for the evaluation of the ARR, where only a bivariate type relationship was present, but not among the three factors (Table 2).

The mean Ct decreased as the parasite concentration increased ( $p: 0.000)$. On the other hand, the target that was related to an average Ct lower was the $\mathrm{kDNA}$, and in the post hoc analysis, differences were always found in the paired evaluation of the average Ct of the targets ( $p$ : 0.000), except for HSP-70 with 18S, specifically in the LoD and ARR (Supplementar Table S3).

\section{DISCUSSION}

In the literature, the detection of Leishmania has been reported by PCR due to its high sensitivity in comparison with traditional parasitological methods (Kumar et al., 2007) and their ability to detect DNA of the parasite in a wide variety of clinical specimens (skin biopsy, ulcer material, blood, bone, bone marrow, lymph nodes, and direct smears) (Pérez et al., 2011; Mohammadiha et al., 2013). For the molecular diagnosis, several primers directed to genetic targets have been evaluated including ITS1, kDNA, HSP70, SSUrRNA, Miniexon among others. These studies only report the operational capabilities of the assays for 


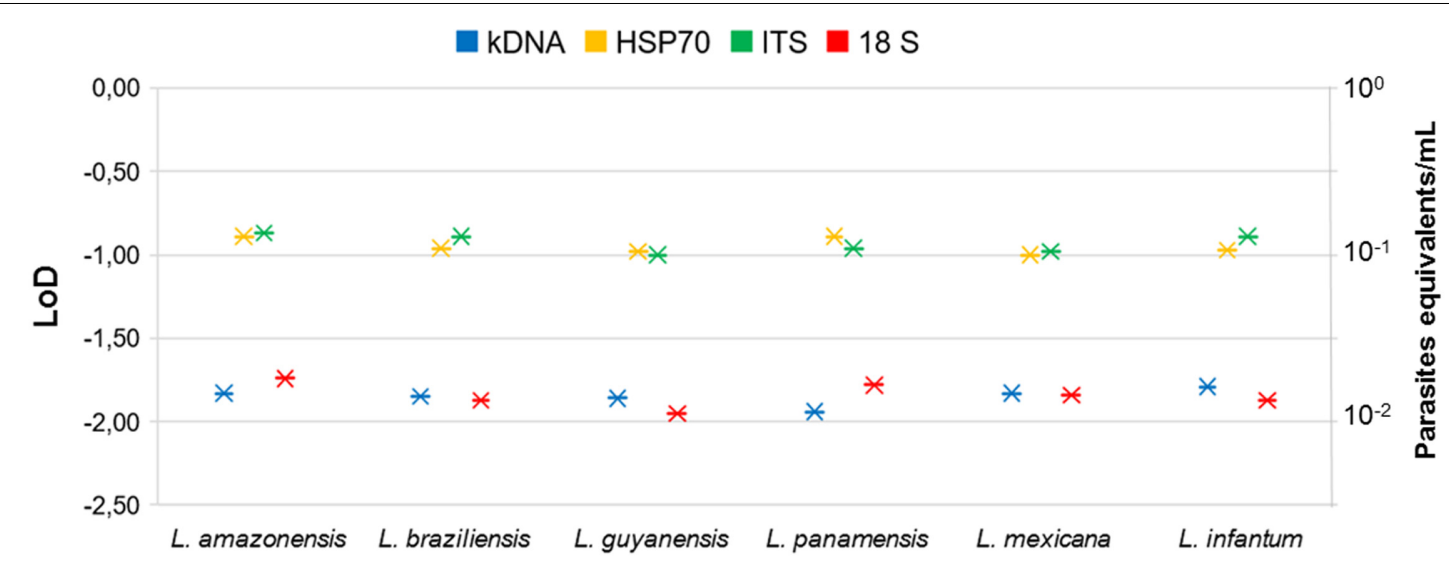

FIGURE 3 | Probit regression to determine LoD of qPCR for the four molecular markers and six Leishmania species.

TABLE 1 | Comparison of the LoD in terms of means, standard deviation, coefficient of variation percentage as a measure of accuracy of the 6 species of Leishmania for each molecular marker by qPCR.

\begin{tabular}{|c|c|c|c|c|c|c|c|c|c|c|c|c|c|}
\hline \multirow[t]{2}{*}{ Marker } & \multirow[t]{2}{*}{ Species } & \multicolumn{3}{|c|}{$\begin{array}{c}10^{-3}(0,001 \text { parasite } \\
\text { equivalents } / \mathrm{mL})\end{array}$} & \multicolumn{3}{|c|}{$\begin{array}{c}10^{-2}(0.01 \text { parasite } \\
\text { equivalents } / \mathrm{mL})\end{array}$} & \multicolumn{3}{|c|}{$\begin{array}{c}10^{-1}(0.1) \text { parasite } \\
\text { equivalents } / \mathrm{mL}\end{array}$} & \multicolumn{3}{|c|}{$\begin{array}{l}10^{0} \text { ( } 1 \text { parasite } \\
\text { equivalent } / \mathrm{mL} \text { ) }\end{array}$} \\
\hline & & $\begin{array}{l}\text { Mean } \\
\text { (Ct) }\end{array}$ & $S D$ & CV\% & $\begin{array}{l}\text { Mean } \\
\text { (Ct) }\end{array}$ & $S D$ & CV\% & $\begin{array}{l}\text { Mean } \\
\text { (Ct) }\end{array}$ & $S D$ & CV\% & $\begin{array}{l}\text { Mean } \\
\text { (Ct) }\end{array}$ & $S D$ & CV\% \\
\hline \multirow[t]{6}{*}{ HSP70 } & L. amazonensis & & & & 33.32 & 1.76 & 5.29 & 29.87 & 0.95 & 3.19 & 27.45 & 0.37 & 1.34 \\
\hline & L. braziliensis & & & & 33.29 & 1.60 & 4.82 & 30.09 & 0.74 & 2.44 & 27.56 & 0.47 & 1.69 \\
\hline & L. guyanensis & & & & 31.88 & 1.79 & 5.60 & 29.92 & 1.01 & 3.36 & 27.5 & 0.52 & 1.88 \\
\hline & L. panamensis & & & & 31.75 & 2.66 & 8.37 & 30.26 & 0.86 & 2.83 & 27.59 & 0.43 & 1.55 \\
\hline & L. mexicana & & & & 33.99 & 1.46 & 4.29 & 30.38 & 0.68 & 2.24 & 28.05 & 0.48 & 1.71 \\
\hline & L. infantum & & & & 34.29 & 2.19 & 6.39 & 30.03 & 0.63 & 2.10 & 27.43 & 0.45 & 1.66 \\
\hline \multirow[t]{6}{*}{ ITS } & L. amazonensis & & & & 36.76 & 0.84 & 2.30 & 34 & 0.37 & 1.07 & 30.14 & 0.37 & 1.24 \\
\hline & L. braziliensis & & & & 36.56 & 0.80 & 2.19 & 34.22 & 0.39 & 1.15 & 30.07 & 0.33 & 1.09 \\
\hline & L. guyanensis & & & & 37.58 & 0.85 & 2.26 & 34.43 & 0.39 & 1.13 & 30.14 & 0.35 & 1.17 \\
\hline & L. panamensis & & & & 37.14 & 0.79 & 2.13 & 33.93 & 0.41 & 1.21 & 30.03 & 0.47 & 1.57 \\
\hline & L. mexicana & & & & 37.55 & 0.65 & 1.74 & 34.48 & 0.39 & 1.14 & 30.21 & 0.44 & 1.46 \\
\hline & L. infantum & & & & 36.77 & 0.75 & 2.03 & 34.38 & 0.43 & 1.26 & 29.98 & 0.36 & 1.21 \\
\hline \multirow[t]{6}{*}{ kDNA } & L. amazonensis & 29.57 & 0.34 & 1.14 & 23.83 & 0.24 & 0.99 & 20.3 & 0.22 & 1.07 & & & \\
\hline & L. braziliensis & 29.85 & 0.31 & 1.04 & 24.52 & 0.11 & 0.46 & 19.46 & 0.20 & 1.00 & & & \\
\hline & L. guyanensis & 30.1 & 0.37 & 1.24 & 24.67 & 0.34 & 1.39 & 19.44 & 0.26 & 1.32 & & & \\
\hline & L. panamensis & 29.99 & 0.45 & 1.49 & 24.54 & 0.26 & 1.09 & 20.18 & 0.21 & 1.05 & & & \\
\hline & L. mexicana & 30.41 & 0.40 & 1.33 & 24.09 & 0.30 & 1.24 & 20.21 & 0.22 & 1.11 & & & \\
\hline & L. infantum & 29.99 & 0.40 & 1.35 & 24.09 & 0.31 & 1.27 & 19.99 & 0.21 & 1.06 & & & \\
\hline \multirow[t]{6}{*}{$18 \mathrm{~S}$} & L. amazonensis & 39.03 & 0.63 & 1.61 & 34.91 & 0.45 & 1.30 & 31.51 & 0.43 & 1.35 & & & \\
\hline & L. braziliensis & 38.74 & 0.56 & 1.44 & 35.03 & 0.37 & 1.05 & 31.27 & 0.39 & 1.24 & & & \\
\hline & L. guyanensis & 38.89 & 0.78 & 2.01 & 34.83 & 0.46 & 1.33 & 31.25 & 0.58 & 1.84 & & & \\
\hline & L. panamensis & 39.06 & 0.49 & 1.24 & 34.72 & 0.41 & 1.17 & 31.44 & 0.45 & 1.44 & & & \\
\hline & L. mexicana & 38.67 & 0.81 & 2.10 & 34.77 & 0.61 & 1.76 & 31.32 & 0.40 & 1.28 & & & \\
\hline & L. infantum & 39.62 & 0.76 & 1.92 & 34.75 & 0.47 & 1.36 & 31.53 & 0.48 & 1.51 & & & \\
\hline
\end{tabular}

unique Leishmania species. Nevertheless, an adequate evaluation of the analytical performance of the techniques and primers directed to the genetic targets has not been yet performed and still mandatory (Berzunza-Cruz et al., 2002; Marfurt et al., 2003; Chargui et al., 2005; Bensoussan et al., 2006; Garcia et al., 2007; Kumar et al., 2007; Ovalle Bracho et al., 2007; Deborggraeve et al., 2008; Al-Hucheimi et al., 2009; Mouttaki et al., 2014; Akhoundi et al., 2017). Only certain studies have evaluated parameters of the technique's exclusivity (Salotra et al., 2001), evaluation of ARR (Jara et al., 2013) and determination 


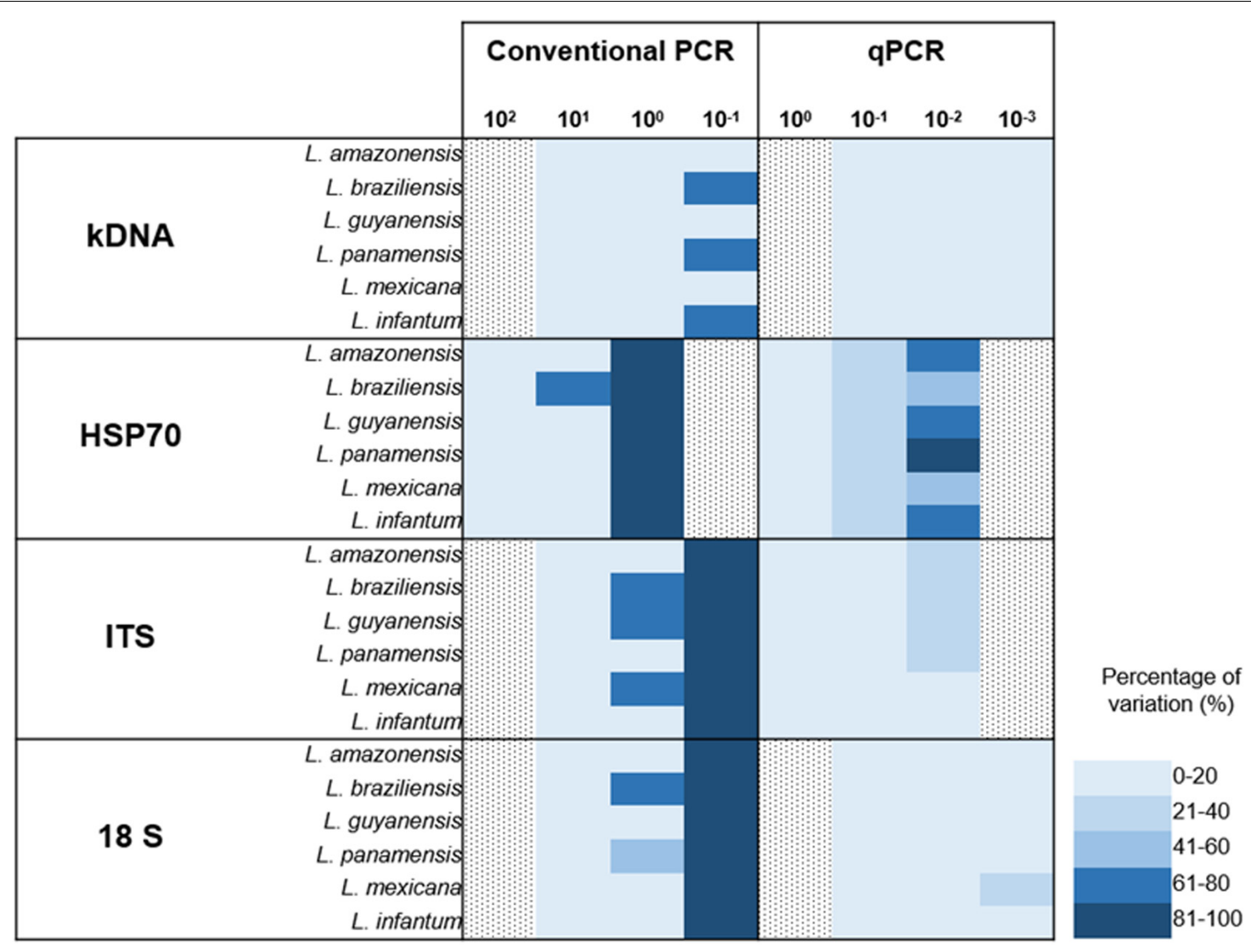

FIGURE 4 | Absolute comparison of percentages of variation in conventional and real time PCR for the four markers employed across the seven species studied.

of LoD (Santamaria et al., 2005; Deborggraeve et al., 2008; Hernández et al., 2014; Hitakarun et al., 2014). Cruz et al. (2013) report the unique multi-center study on the evaluation of diagnostic tools for leishmaniasis. They report the sensitivity of the different molecular methods in four laboratories in endemic areas, concluding that the qPCR with the kDNA gene presented the highest sensitivity, whereas the qPCR directed to the ITS-1 and the digestion with the enzyme HaeIII plus the HSP70 + RLFP combination were the most appropriate targets for species identification (Cruz et al., 2013). Herein, we evaluated for the first time to our knowledge the analytical performance of PCR and qPCR assays using previously reported primers directed to 4 genetic targets in six endemic and causative CL species from the New World. However, it is well known the vast diversity across Leishmania species in the Americas. This is a limitation of our study and further investigations should consider more species.

\section{Analytical Specificity}

Regarding the exclusivity of the technique with the four markers, we observed that the PCR assay herein tested is not exclusive for Leishmania DNA amplification when using the primers selected and directed to $\mathrm{kDNA}$, due to the amplification with DNA of T. cruzi and M. tuberculosis (Supplementary Figure S1). One explaination might be the use of degenerated primers despite of the good performance of these primers in the initial in silico evaluation. These findings contrasts the reported by Salotra et al. (2001), where there was no cross-reaction with M. tuberculosis and M. leprae DNA (Salotra et al., 2001). This has to be considered since there are several reported primers directed to the conserved and hypervariable regions of Leishmania kDNA that do not show cross-reaction with T. cruzi DNA (Gualda et al., 2015; Ceccarelli et al., 2017). Future studies should implement all the reported primers directed to the kDNA to finally conclude if this marker is or not exclusive for Leishmania DNA detection.

The other assays directed to $18 \mathrm{~S}, \mathrm{kDNA}$ and ITS-1 markers were exclusive for Leishmania DNA detection, similar to those results reported by Hitakarun et al. (2014). Several studies include in their molecular tests DNA from cross-reactive microorganisms (Salotra et al., 2001; Deborggraeve et al., 2008; Hitakarun et al., 2014). We included eight microorganisms of differential diagnosis with the four assays, corroborating the results obtained in the conventional PCR when using the primers directed to the kDNA. In qPCR, we also detected the DNA amplification of $T$. cruzi possibly for the close phylogenetic relatedness with Leishmania (de Morais et al., 2015) and M. tuberculosis maybe due to the intraspecies polymorphisms of $\mathrm{kDNA}$ as described by Srivastava et al. (2011) and the presence of subclasses across the minicircle molecules (Ceccarelli et al., 2014). Future studies should include the vast variation of $\mathrm{kDNA}$ primers to rule out 
TABLE 2 | Results of the Factorial ANOVA - Threshold Cycle (Ct) to determine multivariate interactions among target, species and concentration in the ARR, LoD and Accuracy parameters.

\begin{tabular}{|c|c|c|c|}
\hline Condition & df & $\boldsymbol{F}$ & $p$-value \\
\hline \multicolumn{4}{|l|}{ ARR } \\
\hline Target (T) & 3 & 2108.158 & 0.000 \\
\hline Species (S) & 5 & 113.246 & 0.000 \\
\hline Concentration (C) & 6 & 3170.955 & 0.000 \\
\hline $\mathrm{T} * \mathrm{~S}$ & 15 & 31.046 & 0.000 \\
\hline $\mathrm{T}^{*} \mathrm{C}$ & 18 & 10.043 & 0.000 \\
\hline $\mathrm{S}^{*} \mathrm{C}$ & 30 & 4.902 & 0.000 \\
\hline $\mathrm{S}^{*} \mathrm{C}^{*} \mathrm{~T}$ & 90 & 1.781 & 0.014 \\
\hline \multicolumn{4}{|l|}{ LoD } \\
\hline Target $(T)$ & 3 & 13893.279 & 0.000 \\
\hline Species (S) & 5 & 1212.73 & 0.000 \\
\hline Concentration (C) & 4 & 18733.319 & 0.000 \\
\hline $\mathrm{T} * \mathrm{~S}$ & 15 & 192.626 & 0.000 \\
\hline $\mathrm{T} * \mathrm{C}$ & 12 & 79.141 & 0.000 \\
\hline $\mathrm{S}^{*} \mathrm{C}$ & 20 & 47.799 & 0.000 \\
\hline $\mathrm{S}^{*} \mathrm{C}^{*} \mathrm{~T}$ & 60 & 17.816 & 0.000 \\
\hline \multicolumn{4}{|l|}{ Accuracy } \\
\hline Target (T) & 5 & 3.046 & 0.000 \\
\hline Species (S) & 3 & 9735.668 & 0.000 \\
\hline Concentration (C) & 3 & 4317.608 & 0.000 \\
\hline $\mathrm{T} * \mathrm{~S}$ & 15 & 3.965 & 0.000 \\
\hline $\mathrm{T}^{*} \mathrm{C}$ & 15 & 1.171 & 0.000 \\
\hline $\mathrm{S}^{*} \mathrm{C}$ & 5 & 68.932 & 0.000 \\
\hline $\mathrm{S}^{*} \mathrm{C} * \mathrm{~T}$ & 25 & 4.116 & 0.000 \\
\hline
\end{tabular}

our findings and finally decide if kDNA is advisable or not for the molecular diagnosis of Leishmania DNA. However, the primers herein employed were not exclusive. Lastly, no evidence of crossreaction was depicted with the primers herein directed to ITS-1, HSP70 and 18S.

\section{Analytical Sensitivity Conventional PCR}

We determined the analytical sensitivity for PCR in terms of ARR, LoD and accuracy (Figure 1 and Table 1). Santamaria et al. (2005) determined the LoD in 1 equivalent parasite in the PCR using kDNA (Santamaria et al., 2005), unlike the findings of this study, the LoD of this technique with the same marker was $1 \times 10^{-1}$ parasites equivalents $/ \mathrm{mL}$ (Figure 1). These results are consistent with those described by other authors where is reported that $\mathrm{kDNA}$ presents high copy number and can detect up to less than one parasite in conventional PCR (de Bruijn and Barker, 1992; Mary et al., 2004; Francino et al., 2006; Oliveira et al., 2011; Gualda et al., 2015). The LoD for the assays directed to the $18 \mathrm{~S}$ and ITS- 1 markers was $1 \times 10^{\circ}$ parasites equivalents $/ \mathrm{mL}$, similar results reported by Deborggraeve et al. (2008) where the technique was able to detect up to 1 parasite/180 $\mu \mathrm{L}$. On the other hand, the LoD with the HSP70 marker was $1 \times 10^{1}$ parasites equivalents/mL. These findings support the reported in previous studies where the LoD of HSP70 is lower than other molecular markers. This can be explained by the low number of HSP70 copies across the Leishmania genome compared to kDNA and ribosomal markers (Hernández et al., 2014; Hitakarun et al., 2014). Also, this might be explained by the variation across the HSP70 gene in several Leishmania species from the old world and new world (Hernández et al., 2014).

When the same parameters were evaluated in $\mathrm{qPCR}$, it was observed that the technique was more sensitive and reproducible than conventional PCR (Figures 1, 2). Previous studies have described these same findings not only for Leishmania (Pourmohammadi et al., 2010; Sterkers et al., 2010; Eroglu et al., 2014) but for other microorganisms such as Helicobacter pylori (de Bruijn and Barker, 1992), Plasmodium spp (Gama et al., 2007), Salmonella enterica (Parker et al., 2011) and viruses such as ZIKV (Francino et al., 2006) and DENV (Bai et al., 2008; Faye et al., 2013). For the ARR, we observed that when kDNA is used a Ct between 5 and 27 is observed, a much lower range than the one reported for the other molecular markers (Figure 2). According to data reported by Jara et al. (2013), where its amplification range was between a Ct of 7 and 27 (Jara et al., 2013). For the other markers, there was greater variability of the range among strains such as L. panamensis and L. braziliensis in HSP70 and a low efficiency in L. amazonensis and L. guyanensis species in ITS-1 (Figure 2). In general, good reproducibility and efficiency were presented with kDNA and $18 \mathrm{~S}$ genetic targets $\left(R^{2}\right)$ between replicates in accordance with Bezerra-Vasconcelos et al. (2011). However, kDNA is not exclusive and the best analytical performance is finally observed for $18 \mathrm{~S}$.

The qPCR LoD was $1 \times 10^{-2}$ parasites equivalents $/ \mathrm{mL}$ for the kDNA and $18 \mathrm{~S}$ markers, and $1 \times 10^{-1}$ parasites equivalents $/ \mathrm{mL}$ for HSP70 and ITS-1 (Figure 3). These results are consistent with those found by Mary et al. (2004) and Bezerra-Vasconcelos et al. (2011) when using the kDNA, a LoD of 0.0125 parasites $/ \mathrm{mL}$ was reported but contrasts with Nicolas et al. (2002) where they only report a limit of 0.1 parasites. For the ITS-1 marker, a number of copies from 20 to 200 have been estimated in the Leishmania genome and might explain its good performance in low concentrations of parasites (Schonian et al., 2001a,b; Odiwuor et al., 2011). Nevertheless, our results contrast with the reported limit, since the LoD was lower than that found with the $18 \mathrm{~S}$ gene. For the HSP70, LoD was lower in comparison to kDNA and 18S, but higher than that reported by Hernández et al. (2014), where they report a LoD of 10 parasites/mL (Hernández et al., 2014). For this gene, the number of copies present in the different species, although variable, are few, fluctuating between 1 and 15 copies (MacFarlane et al., 1990; Bock and Langer, 1993; Zurita et al., 2003), which could, theoretically, explain the lowest LoD obtained. It is quite unlikely to estimate the LoD of HSP70 as $1 \times 10^{-1}$ equivalent parasites $/ \mathrm{mL}$ due to previous reports of 10-15 copies across the genome. However, herein we used a smaller fragment of HSP70 designed exclusively for the New World species. This might have improved the efficiency of the test that allowed us to reach that LoD. This set of primers has never been applied in the old world Leishmania species. Also, it is currently unknown the precise organization of the HSP70 gene in the New World species. The advent of Genomic studies will provide further insights about the true number of copies and genomic organizations of HSP70 cluster in new world 
species. Nevertheless, this is not sufficient to explain the obtained LoD for HSP70. The accuracy results shows that at this dilution $\left(1 \times 10^{-1}\right.$ parasites equivalent $\left./ \mathrm{mL}\right)$, the percentage of variation was $21-40 \%$ (Figure 4 ) which was not the case for the other markers demonstrating that there is massive variation at the LoD dilution. This could envisage that small DNA fragments of the gene are subject of amplification via the qPCR but no stable equivalent parasites are truly amplified. Therefore, a plausible explanation might be that the LoD is not stable due to massive variation in terms of gene arrangements or intraspecific variation or enough template availability and plausibly suggesting that in future studies this LoD has to be subject of investigation.

The literature reports that each parasite species contains large numbers of copies of the $18 \mathrm{~S}$ ribosomal gene $(\sim 160)$. Therefore, several studies choose this marker as the ideal target for molecular studies. In 2011, Bezerra et al., established a LoD of 40 parasites/mL when using 18S. However, Schulz et al. (2003) reported a LoD of 100 parasites/mL. Our results differ from these two studies in determining a lower LoD for $18 \mathrm{~S}\left(1 \times 10^{-2}\right.$ parasites equivalents $\left./ \mathrm{mL}\right)$. There was no variation in LoD between strains when using this molecular marker (Table 1). The data analyzed by ANOVA with three parameters (Variable result: CT, Fixed factors: concentration, species, marker and Covariable: days) had no effect of the covariate nor of the repetition through the days. The same was found when analyzing the difference between the Ct means obtained ( $P$-value: 0.86) (Supplementary Figure S2). It was also observed that the means comparison tests allowed to identify that the tendency to increase $\mathrm{Ct}$, is dependent on the increase of the dilution, showing a significant difference for all the dilutions and in all the markers $(P$-value $<0.05)$, When comparing the $\mathrm{Ct}$ means of each molecular marker used in each dilution evaluated, it was found that most have a different behavior (statistically significant differences $P$-value $<0.05)$.

For the accuracy, we did not observe variation between the replicates of the tests, independent of the day of execution of the technique (average coefficient of variation of 0.98 ), but when handling lower dilutions the coefficient of variation increases in the days of repetition of the technique. This has been demonstrated in studies evaluating the performance of qPCR in T. cruzi and in Leishmania (Duffy et al., 2013; Jara et al., 2013). The highest coefficient of variation was obtained with the HSP70 marker.

In general, the comparison herein conducted showed the limitations of HSP70 in the detection of Leishmania in terms of sensitivity by PCR and qPCR. Also, the fact that $\mathrm{kDNA}$ is not an exclusive marker due to the amplification for $T$. cruzi and M. tuberculosis DNA (Supplementary Figure S1). Also, the low efficiency of the qPCR using the ITS-1 with L. amazonensis and L. guyanensis species (Figure 2). However, we report the good analytical performance (in terms of accuracy among the species) that the $18 \mathrm{~S}$ marker exhibits for molecular diagnostics. As mentioned initially, studies on the comprehensive evaluation of the analytical performance of molecular methods for the diagnosis of CL are scarce and are affected by the difficulty of not having a consensus of established diagnostic tests. Implementing a molecular technique such as qPCR for field work in endemic areas for leishmaniasis leads to having a special infrastructure as well as the acquisition of costly equipment and reagents (its cost is reported to be up to three times higher than that of conventional PCR) (Bock and Langer, 1993). This reflects the need to develop new technologies more sensitive but easy to acquire and to be implemented in this type of regions, such as LAMP (Notomi et al., 2000; Tomita et al., 2008; Nzelu et al., 2014, 2016; Abbasi et al., 2016) and nanoparticles (Andreadou et al., 2014). Although microscopy remains the gold standard for routine diagnosis, the high incidence of CL in different regions of South America highlights the need to rethink the implementation of specific strategies for the correct and timely diagnosis of this disease. The results herein obtained provide the basis for the subsequent evaluation of the diagnostic performance with a panel of varied samples and its interlaboratory comparison of real-time PCR with the $18 \mathrm{~S}$. We also suggest the inclusion of more species from the Americas. We employed only six species that are the most frequent in CL cases in Colombia but further studies should be considered.

\section{AUTHOR CONTRIBUTIONS}

$\mathrm{CL}, \mathrm{CH}$, and JR conceived and designed the experiments. CL, JC, and JR wrote the manuscript. CL performed the experiments. $\mathrm{MM}$ and AT performed statistical analysis. MM, JR, CH, CF, and MA reviewed and revised the manuscript.

\section{FUNDING}

We thank the Departamento Administrativo de Ciencia, Tecnología e Innovación 'COLCIENCIAS' for funding the Project "Fortalecimiento de la capacidad diagnóstica, de investigación y de vigilancia de enfermedades transmisibles emergentes y reemergentes en Colombia" grant number 757-13.

\section{ACKNOWLEDGMENT}

We thank Fundacion Instituto de Inmunología de Colombia for providing DNA from $M$. tuberculosis.

\section{SUPPLEMENTARY MATERIAL}

The Supplementary Material for this article can be found online at: http://journal.frontiersin.org/article/10.3389/fmicb.2017. 01907/full\#supplementary-material

FIGURE S1 | Conventional PCR amplification in agarose gels (A) KDNA, (B) HSP70, (C) ITS-1, (D) 18S. Left: Exclusivity 1: T. cruzi; 2: T. rangeli; 3: S. aureus; 4: S. pyogenes; 5: H. capsulatum; 6: M. tuberculosis; 7: S. schenckii; 8: F. pedrosoi; 9: positive control; 10: negative control. Right: Inclusivity 1 : L. amazonensis; 2: L. braziliensis; 3: L. guyanensis; 4: L. panamesis; 5: L. mexicana; 6: L. infantum; 7: Negative control.

FIGURE S2 | Differences of the mean Cts for the markers kDNA, HSP70, ITS-1 and $18 \mathrm{~S}$. 


\section{REFERENCES}

Abbasi, I., Kirstein, O. D., Hailu, A., and Warburg, A. (2016). Optimization of loop-mediated isothermal amplification (LAMP) assays for the detection of Leishmania DNA in human blood samples. Acta Trop. 162, 20-26. doi: 10.1016/ j.actatropica.2016.06.009

Adams, E. R., Gomez, M. A., Scheske, L., Rios, R., Marquez, R., Cossio, A., et al. (2014). Sensitive diagnosis of cutaneous leishmaniasis by lesion swab sampling coupled to qPCR. Parasitology 141, 1891-1897. doi: 10.1017/ S0031182014001280

Akhoundi, M., Downing, T., Votypka, J., Kuhls, K., Lukes, J., Cannet, A., et al. (2017). Leishmania infections: molecular targets and diagnosis. Mol. Aspects Med. 57, 1-29. doi: 10.1016/j.mam.2016.11.012

Akhoundi, M., Kuhls, K., Cannet, A., Votypka, J., Marty, P., Delaunay, P., et al. (2016). A historical overview of the classification, evolution, and dispersion of Leishmania parasites and sandflies. PLOS Negl. Trop. Dis. 10:e0004349. doi: 10.1371/journal.pntd.0004349

Al-Hucheimi, S. N., Sultan, B. A., and Al-Dhalimi, M. A. (2009). A comparative study of the diagnosis of Old World cutaneous leishmaniasis in Iraq by polymerase chain reaction and microbiologic and histopathologic methods. Int. J. Dermatol. 48, 404-408. doi: 10.1111/j.1365-4632.2009.03903.x

Alvar, J., Velez, I. D., Bern, C., Herrero, M., Desjeux, P., Cano, J., et al. (2012). Leishmaniasis worldwide and global estimates of its incidence. PLOS ONE 7:e35671. doi: 10.1371/journal.pone.0035671

Andreadou, M., Liandris, E., Gazouli, M., Taka, S., Antoniou, M., Theodoropoulos, G., et al. (2014). A novel non-amplification assay for the detection of Leishmania spp. in clinical samples using gold nanoparticles. J. Microbiol. Methods 96, 56-61. doi: 10.1016/j.mimet.2013.10.011

Bai, Z., Liu, L., Tu, Z., Yao, L., Liu, J., Xu, B., et al. (2008). Real-time PCR for detecting circulating Dengue virus in the Guangdong Province of China in 2006. J. Med. Microbiol. 57, 1547-1552. doi: 10.1099/jmm.0.2008/00 3418-0

Bensoussan, E., Nasereddin, A., Jonas, F., Schnur, L. F., and Jaffe, C. L. (2006). Comparison of PCR assays for diagnosis of cutaneous leishmaniasis. J. Clin Microbiol. 44, 1435-1439. doi: 10.1128/JCM.44.4.1435-1439.2006

Berzunza-Cruz, M., Cabrera, N., Crippa-Rossi, M., Sosa Cabrera, T., PerezMontfort, R., and Becker, I. (2002). Polymorphism analysis of the internal transcribed spacer and small subunit of ribosomal RNA genes of Leishmania mexicana. Parasitol. Res. 88, 918-925. doi: 10.1007/s00436-002-0672-x

Bezerra-Vasconcelos, D. R., Melo, L. M., Albuquerque, E. S., Luciano, M. C., and Bevilaqua, C. M. (2011). Real-time PCR to assess the Leishmania load in Lutzomyia longipalpis sand flies: screening of target genes and assessment of quantitative methods. Exp. Parasitol. 129, 234-239. doi: 10.1016/j.exppara.2011. 08.010

Bock, J. H., and Langer, P. J. (1993). Sequence and genomic organization of the hsp70 genes of Leishmania amazonensis. Mol. Biochem. Parasitol. 62, 187-197. doi: 10.1016/0166-6851(93)90108-A

Boggild, A. K., Ramos, A. P., Espinosa, D., Valencia, B. M., Veland, N., MirandaVerastegui, C., et al. (2010). Clinical and demographic stratification of test performance: a pooled analysis of five laboratory diagnostic methods for American cutaneous leishmaniasis. Am. J. Trop. Med. Hyg. 83, 345-350. doi: 10.4269/ajtmh.2010.09-0414

Burd, E. M. (2010). Validation of laboratory-developed molecular assays for infectious diseases. Clin. Microbiol. Rev. 23, 550-576. doi: 10.1128/CMR. 00074-09

Ceccarelli, M., Galluzzi, L., Diotallevi, A., Andreoni, F., Fowler, H., Petersen, C., et al. (2017). The use of kDNA minicircle subclass relative abundance to differentiate between Leishmania (L.) infantum and Leishmania (L.) amazonensis. Parasit. Vectors 10, 239. doi: 10.1186/s13071-017-2181-x

Ceccarelli, M., Galluzzi, L., Migliazzo, A., and Magnani, M. (2014). Detection and characterization of Leishmania (Leishmania) and Leishmania (Viannia) by SYBR green-based real-time PCR and high resolution melt analysis targeting kinetoplast minicircle DNA. PLOS ONE 9:e88845. doi: 10.1371/journal.pone. 0088845

Chargui, N., Bastien, P., Kallel, K., Haouas, N., Akrout, F. M., Masmoudi, A., et al. (2005). Usefulness of PCR in the diagnosis of cutaneous leishmaniasis in Tunisia. Trans. R. Soc. Trop. Med. Hyg. 99, 762-768. doi: 10.1016/j.trstmh.2005. 06.002
Cruz, I., Canavate, C., Rubio, J. M., Morales, M. A., Chicharro, C., Laguna, F., et al. (2002). A nested polymerase chain reaction (Ln-PCR) for diagnosing and monitoring Leishmania infantum infection in patients co-infected with human immunodeficiency virus. Trans. R. Soc. Trop. Med. Hyg. 96(Suppl. 1), S185-S189. doi: 10.1016/S0035-9203(02)90074-X

Cruz, I., Millet, A., Carrillo, E., Chenik, M., Salotra, P., Verma, S., et al. (2013). An approach for interlaboratory comparison of conventional and real-time PCR assays for diagnosis of human leishmaniasis. Exp. Parasitol. 134, 281-289. doi: 10.1016/j.exppara.2013.03.026

de Bruijn, M. H., and Barker, D. C. (1992). Diagnosis of New World leishmaniasis: specific detection of species of the Leishmania braziliensis complex by amplification of kinetoplast DNA. Acta Trop. 52, 45-58. doi: 10.1016/0001706X(92)90006-J

de Morais, C. G., Castro Lima, A. K., Terra, R., Dos Santos, R. F., Da-Silva, S. A., and Dutra, P. M. (2015). The dialogue of the host-parasite relationship: Leishmania spp. and Trypanosoma cruzi infection. Biomed Res. Int. 2015:324915. doi: 10. $1155 / 2015 / 324915$

Deborggraeve, S., Laurent, T., Espinosa, D., Van Der Auwera, G., Mbuchi, M. Wasunna, M., et al. (2008). A simplified and standardized polymerase chain reaction format for the diagnosis of leishmaniasis. J. Infect. Dis. 198, 1565-1572. doi: 10.1086/592509

Desjeux, P. (2001). The increase in risk factors for leishmaniasis worldwide. Trans. R. Soc. Trop. Med. Hyg. 95, 239-243. doi: 10.1016/S0035-9203(01) 90223-8

Duffy, T., Cura, C. I., Ramirez, J. C., Abate, T., Cayo, N. M., Parrado, R., et al. (2013). Analytical performance of a multiplex Real-Time PCR assay using TaqMan probes for quantification of Trypanosoma cruzi satellite DNA in blood samples. PLOS Negl. Trop. Dis. 7:e2000. doi: 10.1371/journal.pntd.00 02000

el Tai, N. O., Osman, O. F., El Fari, M., Presber, W., and Schonian, G. (2000) Genetic heterogeneity of ribosomal internal transcribed spacer in clinical samples of Leishmania donovani spotted on filter paper as revealed by singlestrand conformation polymorphisms and sequencing. Trans. R. Soc. Trop. Med. Hyg. 94, 575-579. doi: 10.1016/S0035-9203(00)90093-2

Eroglu, F., Uzun, S., and Koltas, I. S. (2014). Comparison of clinical samples and methods in chronic cutaneous leishmaniasis. Am. J. Trop. Med. Hyg. 91, 895-900. doi: 10.4269/ajtmh.13-0582

Faye, O., Diallo, D., Diallo, M., Weidmann, M., and Sall, A. A. (2013). Quantitative real-time PCR detection of Zika virus and evaluation with field-caught mosquitoes. Virol. J. 10:311. doi: 10.1186/1743-422X-10-311

Francino, O., Altet, L., Sanchez-Robert, E., Rodriguez, A., Solano-Gallego, L., Alberola, J., et al. (2006). Advantages of real-time PCR assay for diagnosis and monitoring of canine leishmaniosis. Vet. Parasitol. 137, 214-221. doi: 10.1016/ j.vetpar.2006.01.011

Gama, B. E., Silva-Pires Fdo, E., Lopes, M. N., Cardoso, M. A., Britto, C., Torres, K. L., et al. (2007). Real-time PCR versus conventional PCR for malaria parasite detection in low-grade parasitemia. Exp. Parasitol. 116, 427-432. doi: 10.1016/ j.exppara.2007.02.011

Garcia, A. L., Parrado, R., De Doncker, S., Bermudez, H., and Dujardin, J. C. (2007). American tegumentary leishmaniasis: direct species identification of Leishmania in non-invasive clinical samples. Trans. R. Soc. Trop. Med. Hyg. 101, 368-371. doi: 10.1016/j.trstmh.2006.06.009

Goto, H., and Lauletta Lindoso, J. A. (2012). Cutaneous and mucocutaneous leishmaniasis. Infect. Dis. Clin. North Am. 26, 293-307. doi: 10.1016/j.idc.2012. 03.001

Gualda, K. P., Marcussi, L. M., Neitzke-Abreu, H. C., Aristides, S. M., Lonardoni, M. V., Cardoso, R. F., et al. (2015). New primers for detection of Leishmania infantum using polymerase chain reaction. Rev. Inst. Med. Trop. Sao Paulo 57, 377-383. doi: 10.1590/S0036-46652015000500002

Hashiguchi, Y., Velez, L. N., Villegas, N. V., Mimori, T., Gomez, E. A., and Kato, H. (2017). Leishmaniases in Ecuador: comprehensive review and current status. Acta Trop. 166, 299-315. doi: 10.1016/j.actatropica.2016.11.039

Hernández, C., Alvarez, C., Gonzalez, C., Ayala, M. S., Leon, C. M., and Ramirez, J. D. (2014). Identification of six New World Leishmania species through the implementation of a High-Resolution Melting (HRM) genotyping assay. Parasit. Vectors 7, 501. doi: 10.1186/s13071-014-0501-y

Hitakarun, A., Tan-Ariya, P., Siripattanapipong, S., Mungthin, M., Piyaraj, P., Naaglor, T., et al. (2014). Comparison of PCR methods for detection of 
Leishmania siamensis infection. Parasit. Vectors 7:458. doi: 10.1186/s13071014-0458-x

Jara, M., Adaui, V., Valencia, B. M., Martinez, D., Alba, M., Castrillon, C., et al. (2013). Real-time PCR assay for detection and quantification of Leishmania (Viannia) organisms in skin and mucosal lesions: exploratory study of parasite load and clinical parameters. J. Clin. Microbiol. 51, 1826-1833. doi: 10.1128/ JCM.00208-13

Kumar, R., Bumb, R. A., Ansari, N. A., Mehta, R. D., and Salotra, P. (2007). Cutaneous leishmaniasis caused by Leishmania tropica in Bikaner, India: parasite identification and characterization using molecular and immunologic tools. Am. J. Trop. Med. Hyg. 76, 896-901.

MacFarlane, J., Blaxter, M. L., Bishop, R. P., Miles, M. A., and Kelly, J. M. (1990). Identification and characterization of a Leishmania donovani antigen belonging to the $70-\mathrm{kDa}$ heat-shock protein family. Eur. J. Biochem. 190, 377-384. doi: 10.1111/j.1432-1033.1990.tb15586.x

Marfurt, J., Nasereddin, A., Niederwieser, I., Jaffe, C. L., Beck, H. P., and Felger, I. (2003). Identification and differentiation of Leishmania species in clinical samples by PCR amplification of the miniexon sequence and subsequent restriction fragment length polymorphism analysis. J. Clin. Microbiol. 41, 3147-3153. doi: 10.1128/JCM.41.7.3147-3153.2003

Marques, M. J., Volpini, A. C., Genaro, O., Mayrink, W., and Romanha, A. J. (2001). Simple form of clinical sample preservation and Leishmania DNA extraction from human lesions for diagnosis of American cutaneous leishmaniasis via polymerase chain reaction. Am. J. Trop. Med. Hyg. 65, 902-906. doi: 10.4269/ ajtmh.2001.65.902

Mary, C., Faraut, F., Lascombe, L., and Dumon, H. (2004). Quantification of Leishmania infantum DNA by a real-time PCR assay with high sensitivity. J. Clin. Microbiol. 42, 5249-5255. doi: 10.1128/JCM.42.11.5249-52 55.2004

Medeiros, A. R., Silva, W. A. Jr., and Roselino, A. M. (2008). DNA sequencing confirms the involvement of Leishmania (L.) amazonensis in American tegumentary leishmaniasis in the state of Sao Paulo, Brazil. Clinics 63, 451-456. doi: 10.1590/S1807-59322008000400007

Mohammadiha, A., Mohebali, M., Haghighi, A., Mahdian, R., Abadi, A. R., Zarei, Z., et al. (2013). Comparison of real-time PCR and conventional PCR with two DNA targets for detection of Leishmania (Leishmania) infantum infection in human and dog blood samples. Exp. Parasitol. 133, 89-94. doi: 10.1016/j.exppara.2012.10.017

Montalvo, A. M., Fraga, J., El Safi, S., Gramiccia, M., Jaffe, C. L., Dujardin, J. C., et al. (2014). Direct Leishmania species typing in Old World clinical samples: evaluation of 3 sensitive methods based on the heatshock protein 70 gene. Diagn. Microbiol. Infect. Dis. 80, 35-39. doi: 10.1016/j.diagmicrobio.2014.05.012

Motazedian, H., Karamian, M., Noyes, H. A., and Ardehali, S. (2002). DNA extraction and amplification of Leishmania from archived, Giemsastained slides, for the diagnosis of cutaneous Leishmaniasis by PCR. Ann. Trop. Med. Parasitol. 96, 31-34. doi: 10.1179/000349802125 000484

Mouttaki, T., Morales-Yuste, M., Merino-Espinosa, G., Chiheb, S., Fellah, H., Martin-Sanchez, J., et al. (2014). Molecular diagnosis of cutaneous leishmaniasis and identification of the causative Leishmania species in Morocco by using three PCR-based assays. Parasit. Vectors 7:420. doi: 10.1186/1756-33 05-7-420

Munoz, E. B., Santander, S., Rojas-Silva, P., Cardenas, P. A., Fornasini, M., Cifuentes, S. C., et al. (2016). Diagnostic efficacy of molecular techniques for detection and identification of Leishmania species in human whole blood and skin samples from Ecuador. Am. J. Trop. Med. Hyg. 95, 803-805. doi: 10.4269/ ajtmh.16-0385

NCCLS (2004). Protocols for Determination of Limits of Detection and Limits of Quantification: Approved Guideline, Vol. 24. Wayne, PA: Clinical and Laboratory Standards Institute, 2-18.

Nicolas, L., Milon, G., and Prina, E. (2002). Rapid differentiation of Old World Leishmania species by LightCycler polymerase chain reaction and melting curve analysis. J. Microbiol. Methods 51, 295-299. doi: 10.1016/S0167-7012(02) 00099-4

Notomi, T., Okayama, H., Masubuchi, H., Yonekawa, T., Watanabe, K., Amino, N., et al. (2000). Loop-mediated isothermal amplification of DNA. Nucleic Acids Res. 28:e63. doi: 10.1093/nar/28.12.e63
Nzelu, C. O., Caceres, A. G., Guerrero-Quincho, S., Tineo-Villafuerte, E., Rodriquez-Delfin, L., Mimori, T., et al. (2016). A rapid molecular diagnosis of cutaneous leishmaniasis by colorimetric malachite green-loop-mediated isothermal amplification (LAMP) combined with an FTA card as a direct sampling tool. Acta Trop. 153, 116-119. doi: 10.1016/j.actatropica.2015.10.013

Nzelu, C. O., Gomez, E. A., Caceres, A. G., Sakurai, T., Martini-Robles, L., Uezato, H., et al. (2014). Development of a loop-mediated isothermal amplification method for rapid mass-screening of sand flies for Leishmania infection. Acta Trop. 132, 1-6. doi: 10.1016/j.actatropica.2013.12.016

Odiwuor, S. O., Saad, A. A., De Doncker, S., Maes, I., Laurent, T., El Safi, S., et al. (2011). Universal PCR assays for the differential detection of all Old World Leishmania species. Eur. J. Clin. Microbiol. Infect. Dis. 30, 209-218. doi: 10.1007/s10096-010-1071-3

Oliveira, D. M., Lonardoni, M. V., Teodoro, U., and Silveira, T. G. (2011). Comparison of different primes for PCR-based diagnosis of cutaneous leishmaniasis. Braz. J. Infect. Dis. 15, 204-210.

Ovalle Bracho, C., Porras de Quintana, L., Muvdi Arenas, S., and Rios Parra, M. (2007). Polymerase chain reaction with two molecular targets in mucosal leishmaniasis' diagnosis: a validation study. Mem. Inst. Oswaldo Cruz 102, 549-554. doi: 10.1590/S0074-02762007005000061

Pan American Health Organization, [WHO] (2013). Leishmaniases: Epidemiological Report of the Americas. Report No. 1. Washington, DC: Pan American Health Organization.

Parker, W. D., Lungu, B., Berghaus, R. D., Sellers, H. S., Alvarado, I. R., and Hofacre, C. L. (2011). Comparison of real-time PCR with conventional PCR and culture to assess the efficacy of a live attenuated Salmonella enterica serovar Typhimurium vaccine against Salmonella enterica serovar Enteritidis in commercial leghorn chicks vaccinated under field and laboratory conditions. Avian Dis. 55, 248-254. doi: 10.1637/9561-100410-Reg.1

Pérez, D. B., Sosa Tordoya, L. F., and Choquehuanca Quispe, J. L. (2011). Diagnosis of cutaneous leishmaniasis by Polymerase Chain Reaction, using genetic material derived from smears of lesions stained with Giemsa. BIOFARBO 19, 28-38.

Pourmohammadi, B., Motazedian, M., Hatam, G., Kalantari, M., Habibi, P., and Sarkari, B. (2010). Comparison of three methods for diagnosis of cutaneous leishmaniasis. Iran. J. Parasitol. 5, 1-8.

Ramirez, J. C., Cura, C. I., Da Cruz Moreira, O., Lages-Silva, E., Juiz, N., Velazquez, E., et al. (2015). Analytical validation of quantitative real-time PCR methods for quantification of Trypanosoma cruzi DNA in blood samples from Chagas disease patients. J. Mol. Diagn. 17, 605-615. doi: 10.1016/j.jmoldx.2015. 04.010

Ramirez, J. D., Hernandez, C., Leon, C. M., Ayala, M. S., Florez, C., and Gonzalez, C. (2016). Taxonomy, diversity, temporal and geographical distribution of Cutaneous Leishmaniasis in Colombia: a retrospective study. Sci. Rep. 6:28266. doi: 10.1038/srep28266

Reithinger, R., and Dujardin, J. C. (2007). Molecular diagnosis of leishmaniasis: current status and future applications. J. Clin. Microbiol. 45, 21-25. doi: 10. 1128/JCM.02029-06

Rodriguez, N., De Lima, H., Aguilar, C. M., Rodriguez, A., Barker, D. C., and Convit, J. (2002). Molecular epidemiology of cutaneous leishmaniasis in Venezuela. Trans. R. Soc. Trop. Med. Hyg. 96(Suppl. 1), S105-S109. doi: 10. 1016/S0035-9203(02)90060-X

Salotra, P., Sreenivas, G., Pogue, G. P., Lee, N., Nakhasi, H. L., Ramesh, V., et al. (2001). Development of a species-specific PCR assay for detection of Leishmania donovani in clinical samples from patients with kala-azar and postkala-azar dermal leishmaniasis. J. Clin. Microbiol. 39, 849-854. doi: 10.1128/ JCM.39.3.849-854.2001

Santamaria, E., Ponce, N., Puerta, C., and Ferro, C. (2005). Validation of PCR as a tool for the detection of Leishmania (Vianna) spp. parasites in the Lutzomyia (Diptera: Psychodidae) vector. Biomedica 25, 271-279. doi: 10.7705/biomedica. v25i2.1349

Schonian, G., El Fari, M., Lewin, S., Schweynoch, C., and Presber, W. (2001a). Molecular epidemiology and population genetics in Leishmania. Med. Microbiol. Immunol. 190, 61-63.

Schonian, G., Schnur, L., El Fari, M., Oskam, L., Kolesnikov, A. A., SokolowskaKohler, W., et al. (2001b). Genetic heterogeneity in the species Leishmania tropica revealed by different PCR-based methods. Trans. R. Soc. Trop. Med. Hyg. 95, 217-224. 
Schulz, A., Mellenthin, K., Schonian, G., Fleischer, B., and Drosten, C. (2003). Detection, differentiation, and quantitation of pathogenic Leishmania organisms by a fluorescence resonance energy transfer-based real-time PCR assay. J. Clin. Microbiol. 41, 1529-1535. doi: 10.1128/JCM.41.4.1529-1535.2003

Shahbazi, F., Shahabi, S., Kazemi, B., Mohebali, M., Abadi, A. R., and Zare, Z. (2008). Evaluation of PCR assay in diagnosis and identification of cutaneous leishmaniasis: a comparison with the parasitological methods. Parasitol. Res. 103, 1159-1162. doi: 10.1007/s00436-008-1111-4

Srivastava, P., Mehrotra, S., Tiwary, P., Chakravarty, J., and Sundar, S. (2011). Diagnosis of Indian visceral leishmaniasis by nucleic acid detection using PCR. PLOS ONE 6:e19304. doi: 10.1371/journal.pone.0019304

Sterkers, Y., Varlet-Marie, E., Cassaing, S., Brenier-Pinchart, M. P., Brun, S., Dalle, F., et al. (2010). Multicentric comparative analytical performance study for molecular detection of low amounts of Toxoplasma gondii from simulated specimens. J. Clin. Microbiol. 48, 3216-3222. doi: 10.1128/JCM.02 500-09

Szargiki, R., Castro, E. A., Luz, E., Kowalthuk, W., Machado, A. M., and ThomazSoccol, V. (2009). Comparison of serological and parasitological methods for cutaneous leishmaniasis diagnosis in the state of Parana, Brazil. Braz. J. Infect. Dis. 13, 47-52. doi: 10.1590/S1413-86702009000100011
Tomita, N., Mori, Y., Kanda, H., and Notomi, T. (2008). Loop-mediated isothermal amplification (LAMP) of gene sequences and simple visual detection of products. Nat. Protoc. 3, 877-882. doi: 10.1038/nprot.2008.57

Zurita, A. I., Rodríguez, J., Piñero, J. E., Pacheco, R., Carmelo, E., del Castllo, A., et al. (2003). Cloning and characterization of the Leishmania (Viannia) braziliensis Hsp70 gene. Diagnostic use of the C-terminal fragment rLb70(513-663). J. Parasitol. 89, 372-378. doi: 10.1645/0022-3395(2003) 089[0372:CACOTL]2.0.CO;2

Conflict of Interest Statement: The authors declare that the research was conducted in the absence of any commercial or financial relationships that could be construed as a potential conflict of interest.

Copyright (C) 2017 León, Muñoz, Hernández, Ayala, Flórez, Teherán, Cubides and Ramirez. This is an open-access article distributed under the terms of the Creative Commons Attribution License (CC BY). The use, distribution or reproduction in other forums is permitted, provided the original author(s) or licensor are credited and that the original publication in this journal is cited, in accordance with accepted academic practice. No use, distribution or reproduction is permitted which does not comply with these terms. 